\title{
Effect of Additives on the Preferential Crystallization of L-Asparagine monohydrate
}

Peetikamol Kongsamai ${ }^{1}$, Atthaphon Maneedaeng ${ }^{1}$, Chalongsri Flood ${ }^{1}$, Joop H. ter Horst ${ }^{2}$, Adrian E. Flood ${ }^{3}$

${ }^{1}$ School of Chemical Engineering, Suranaree University of Technology, 111 University Avenue, Nakhon Ratchasima, THAILAND;

${ }^{2}$ EPSRC Centre for Innovative Manufacturing in Continuous Manufacturing and Crystallisation (CMAC), Strathclyde Institute of Pharmacy and Biomedical Sciences, Technology and Innovation Centre, University of Strathclyde, 99 George Street, Glasgow G1 1RD, U.K.;

${ }^{3}$ Department of Chemical and Biomolecular Engineering, School of Energy Science and Engineering, Vidyasirimedhi Institute of Science and Technology, 555 Moo 1, Payupnai, Wang Chan, Rayong 21210, THAILAND

Corresponding author: Adrian Flood. Email: adrian.f.vistec@gmail.com. Phone: +66 33 014253. Fax: +66 33014445.

\begin{abstract}
Preferential Crystallization (PC) is a popular process to separate enantiomers, however the nucleation and growth of the counter enantiomer during the process can compromise the enantiopurity of the final crystalline product. This research investigates the use of additives to inhibit the nucleation and growth of the counter enantiomer. In this study, we use Lasparagine monohydrate $\left(\mathrm{L}-\mathrm{Asn} \cdot \mathrm{H}_{2} \mathrm{O}\right)$ as the preferred enantiomer in crystallization from DLAsn $\cdot \mathrm{H}_{2} \mathrm{O}$ solutions. Additives include both pure enantiomers of several related amino acid species. This allows investigation of differences in inhibition caused by additives that are of the same chirality and different chirality as the preferred enantiomer. The additives had no discernible effect on the solubility but had a small effect on the metastable limit, with additives tending to slightly widen the metastable zone but also make the zone widths more disperse. D-additives have a small effect on the growth rate of $\mathrm{L}-\mathrm{Asn} \cdot \mathrm{H}_{2} \mathrm{O}$ but L-Asp and L-
\end{abstract}


Glu strongly inhibit the growth rate of L-Asn $\cdot \mathrm{H}_{2} \mathrm{O}$ in DL-Asn $\cdot \mathrm{H}_{2} \mathrm{O}$ solution; there must also be a corresponding effect for D-Asp and D-Glu on D-Asn $\cdot \mathrm{H}_{2} \mathrm{O}$. Indeed, PC experiments showed that in order to obtain $\mathrm{L}-\mathrm{Asn} \cdot \mathrm{H}_{2} \mathrm{O}$ from a PC while preventing the formation of DAsn $\cdot \mathrm{H}_{2} \mathrm{O}$, D-Asp and D-Glu are suitable additives, leading to high yield and purity of pure L$\mathrm{Asn} \cdot \mathrm{H}_{2} \mathrm{O}$.

\section{Introduction}

Many products in pharmaceutical, food and agrochemical industries are chiral compounds. The two enantiomers of a chiral compound are two stereoisomers and the two molecules are non-superimposable mirror images [1]. The pair of enantiomers have identical physical and chemical properties (apart from the optical rotation) in achiral solvents but are different in biological activities [2]. In the chemical synthesis of chiral materials the product of the synthesis is usually a racemic mixture of enantiomers; $50 \%$ is the preferred enantiomer and $50 \%$ is the counter enantiomer. Normally, the counter enantiomer has no beneficial effect but does increase the drug loading on the body. In some cases the counter enantiomer is harmful; R-thalidomide was used as a sedative and sleeping drug for pregnant women, however, S-thalidomide was found to be teratogenic and caused birth defects in thousands of babies [3]. Therefore the separation of enantiomers is essential in many industries, but particularly in the pharmaceutical industry.

There are many processes to separate enantiomers. Chiral membrane separation uses a chiral-modified membrane which allows the desired enantiomer to selectively diffuse through or adsorb onto the membrane [4]. Chiral chromatography separation uses an enantioselective chiral stationary phase to separate enantiomers [5,6]. However, crystallization has unprecedented selectivity and potentially leads to an enantiopure product within a single process step if the crystallization of the counter enantiomer can be avoided. This can be done through the formation of diastereomeric salts which changes the enantiomers to diastereomers which have different physical properties and enables separation by crystallization [7]. However, this requires an additional separation step to recover the resolving agent.

Preferential crystallization (PC) is a single step process that is easy and low cost for separating enantiomers. This process is suitable for separation of a racemic mixture that is a conglomerate forming system, meaning the equilibrium product is a mechanical mixture of the two enantiomorphs [8]. PC achieves separation in a single process step through seeding the preferred enantiomer to the supersaturated racemic solution; the preferred enantiomer will crystallize at a higher rate than the counter enantiomer, and significant yield and enantiopurity 
can be achieved if the nucleation and growth of the counter enantiomer from the supersaturated solution can be avoided. PC has been applied to chiral species such as glutamic acid [9], asparagine [10], threonine [11] and methionine hydrochloride [12]. However, this method has a serious problem which is the spontaneous nucleation and growth of the counter enantiomer. This may occur after prolonged batch times where the solution has a high supersaturation of the counter enantiomer in comparison to the preferred enantiomer [11]. Many researchers have tried to circumvent this problem, for instance by using coupled batch crystallizers - crystallizing the preferred enantiomer in one crystallizer and the counter enantiomer in another crystallizer, with exchange of solution between the two crystallizers [13], coupled batch crystallizers with seeding of the preferred enantiomer in one crystallizer and allowing nucleation of the counter enantiomer in another crystallizer maintained at a different temperature $[14,15]$, coupled batch crystallizers with a membrane between the crystallizers to prevent transport of crystals from one crystallizer to another [16], and racemization of the solute species to equalize the concentrations of the preferred and counter enantiomer $[17,18]$,

Another way to circumvent the crystallization of the counter enantiomer is to use tailor made additives to inhibit the nucleation and growth of the counter enantiomer. This will be convenient if the scale of the resolution is such that a fully batch system is most suitable and crystallization or recycling of the counter enantiomer is not required. A tailor made additive is any additive which is intelligently designed to change the crystallization process in a desired way. It may inhibit either growth or nucleation, or more rarely promote growth or nucleation, or it may alter the shape or morphology of the crystals. Addadi et al. proposed the rule of reversal, which suggests that additives most easily adsorb on the surface of the crystal that has the same absolute configuration as the additive [19,20]. The rule thus states that the chiral additive will inhibit the crystallization of the enantiomorph similar in chirality to the additive. There are many studies about effect of tailor made additives to the crystallization such as effect of D- and L-lysine additives on DL-glutamic acid [9,21,22].

We are interested in the technique of preferential crystallization using tailor made additives because it uses only a small amount of additive and is easier to operate than other techniques. However how the mechanism by which the additives affect the preferential crystallization, or more specifically the mechanism by which additives reduce the crystallization rate of the counter enantiomer is not known. The present research investigates the solubility and metastable zone width, and both the nucleation and crystal growth processes 
in the presence and absence of additives in an attempt to determine which of the crystallization mechanisms is altered by the presence of the additive.

Doki et al. investigated the effect of pure enantiomeric amino acid additives on the enantiomeric purity of asparagine crystals obtained from racemic solutions [23]. In these unseeded crystallizations they observed a significant delay in the crystallization of the counter enantiomer, indicating that asparagine is an interesting model compound to investigate the effect of chiral additives on asparagine PC. Therefore, following the rule of reversal, we further investigate the preferential crystallization process of L-asparagine monohydrate (LAsn $\cdot \mathrm{H}_{2} \mathrm{O}$ ) from DL-Asn $\cdot \mathrm{H}_{2} \mathrm{O}$ by using D- and L-amino acid additives which have a similar structure to asparagine. We also investigate the efficiency and yield of the preferential crystallization when using additives. To explain the observed effects we separately study the effect of additives on the solubility, metastable zone width and the growth rate.

\section{Experimental Methods}

\subsection{Materials}

DL-asparagine monohydrate $(99+\mathrm{wt} \%)$, L-asparagine monohydrate $(99+\mathrm{wt} \%)$ and Dasparagine monohydrate (99+ wt\%), were purchased from Sigma-Aldrich. D-(-)-aspartic acid (99+wt\%), D-(-)-glutamic acid (99+wt\%), D-valine (98+wt\%), D-leucine (99 wt\%), L-(+)aspartic acid (98+wt\%), L-(+)-glutamic acid (99+wt\%), L-valine (98+wt\%), and L-leucine (99 wt \%) were purchased from ACROS. These reagents were used without further purification. Deionized water was used as the solvent.

\subsection{Experimental Procedure}

\subsubsection{Solubility and Metastable Zone Width}

The solubility and the metastable zone limit of $\mathrm{L}-\mathrm{Asn} \cdot \mathrm{H}_{2} \mathrm{O}$ with and without additives were determined using the Crystal16 (Technobis, Amsterdam). Samples were prepared with a known concentration of Asn $\cdot \mathrm{H}_{2} \mathrm{O}$ in $1 \mathrm{~g}$ of water. To determine the clear point temperature (the temperature at which the suspension turns into a clear solution upon heating), the suspension in the vial was heated with a heating rate of $0.1^{\circ} \mathrm{C} / \mathrm{min}$ up to $60^{\circ} \mathrm{C}$ to complete dissolution. The temperature at which the turbidity reached zero was recorded. To determine the cloud point temperature (the temperature at which the clear solution turns into a suspension upon cooling), the clear solution was subsequently cooled down to $2^{\circ} \mathrm{C}$ with a cooling rate of $0.1^{\circ} \mathrm{C} / \mathrm{min}$. The clear point temperature was taken as the saturation 
temperature of the solution while the cloud point was taken as the metastable limit of the solution for the cooling rate used. The region between the saturation temperature and the highest metastable zone limit measured for a sample was taken as the metastable zone region. For the results, two or three measurements were performed subsequently with the same solution.

\subsubsection{Single Crystal Growth Rate Experiments}

Stock suspensions with various amounts of DL-Asn $\cdot \mathrm{H}_{2} \mathrm{O}$ in the presence and absence of various additives were prepared at $30^{\circ} \mathrm{C}$ and heated up to $58^{\circ} \mathrm{C}$ to completely dissolve the solute. When needed, the solution was cooled to the crystallization temperature, $30^{\circ} \mathrm{C}$. Nine crystals of L-Asn $\cdot \mathrm{H}_{2} \mathrm{O}$ were attached by glue to a cover glass that was placed in a $50 \mathrm{~cm}^{3}$ small cell which was temperature-controlled using a jacket on the cell which used water from a constant temperature bath. The experimental set up is shown in Fig. 1. The growth process of $\mathrm{L}-\mathrm{Asn} \cdot \mathrm{H}_{2} \mathrm{O}$ was initiated when we added the solution to the cell. The size of the crystal was measured every 10 minutes until 80 minutes using a microscope and the DinoCapture 2.0 program. We analyzed the concentration in the cell using an automatic digital refractometer (RFM 340, Bellingham+Stanley Ltd., UK). We investigated the growth rate of L-Asn $\cdot \mathrm{H}_{2} \mathrm{O}$ crystals using supersaturation ratios $(S)$ of $1.05,1.10$ and 1.15 for $\mathrm{L}-\mathrm{Asn} \cdot \mathrm{H}_{2} \mathrm{O}$ and DLAsn $\cdot \mathrm{H}_{2} \mathrm{O}$ solutions. For investigation of the effect of additives we used 3 mol\% of additives based on the total concentration of $\mathrm{DL}-\mathrm{AsnH}_{2} \mathrm{O}$ in solution at a supersaturation ratio $(S)$ of 1.1 .

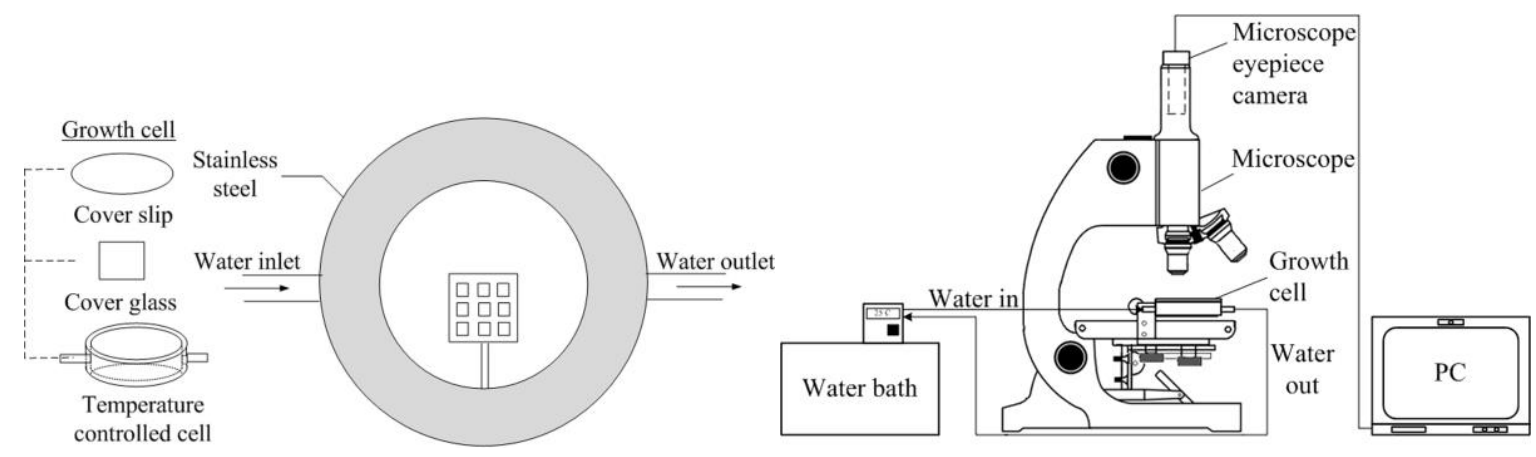

(a)

(b)

Figure 1. The experimental set up of growth rate experiment (a) crystal growth cell and (b) experimental set up

\subsubsection{Preferential Crystallization}


The preferential crystallization of $\mathrm{L}-\mathrm{Asn} \cdot \mathrm{H}_{2} \mathrm{O}$ (the preferred enantiomer) from DLAsn $\cdot \mathrm{H}_{2} \mathrm{O}$ was performed, and additives were used to inhibit D-Asn $\cdot \mathrm{H}_{2} \mathrm{O}$ (the counter enantiomer). We prepared a solution of DL-Asn $\cdot \mathrm{H}_{2} \mathrm{O}$ with a supersaturation ratio $(S)$ of 1.3 at $30^{\circ} \mathrm{C}$ in $40 \mathrm{~g}$ of water in a $50 \mathrm{~mL}$ crystallization vessel with jacket to control the temperature. Additives were added to the solution at $5 \mathrm{~mol} \%$ compared to the total amount of DLAsn $\cdot \mathrm{H}_{2} \mathrm{O}$. The solution was heated to $50^{\circ} \mathrm{C}$ to completely dissolve the crystalline material. Subsequently, the solution was cooled down rapidly to the crystallization temperature of $30^{\circ} \mathrm{C}$. L-Asn $\cdot \mathrm{H}_{2} \mathrm{O}$ seeds, $0.02 \mathrm{~g}$ (300-500 micron) were added into the solution the moment the crystallization temperature reached $30^{\circ} \mathrm{C}$. The process was stopped at a given time and the suspension was vacuum filtered to obtain crystal samples at different times from $1 \mathrm{~h}$ to $7 \mathrm{~h}$ after the addition of seeds. The solid product was kept in a desiccator for drying. The solid products were analysed by HPLC (1260 Infinity, Agilent Technologies) with a Chirobiotic T column. The HPLC analysis was performed at $25^{\circ} \mathrm{C}$ using a $70: 30$ vol\% ethanol:water mixture as a mobile phase at $0.4 \mathrm{~mL} / \mathrm{min}$, and using UV detection at $205 \mathrm{~nm}$. The injection volume was $5 \mu \mathrm{L}$. Under these conditions the detection time for $\mathrm{L}-\mathrm{Asn} \cdot \mathrm{H}_{2} \mathrm{O}$ was $18 \mathrm{~min}$ and the retention time of $\mathrm{D}-\mathrm{Asn} \cdot \mathrm{H}_{2} \mathrm{O}$ was $27 \mathrm{~min}$.

\section{Results and Discussion}

First the solubility and metastable zone limit are presented, followed by the crystal growth rate experiments in the presence and absence of the additives. Finally, preferential crystallization of L-Asn $\cdot \mathrm{H}_{2} \mathrm{O}$ in DL-Asn $\cdot \mathrm{H}_{2} \mathrm{O}$ with and without additives is discussed.

\subsection{Solubility and Metastable Zone Width}

Asparagine monohydrate is a conglomerate forming system [24] which is suitable for the PC process [6]. The solubility and metastable zone width of L-Asn $\cdot \mathrm{H}_{2} \mathrm{O}$, DL-Asn $\cdot \mathrm{H}_{2} \mathrm{O}$ and LAsn $\cdot \mathrm{H}_{2} \mathrm{O}$ with $5 \%$ additives is shown in Figure 2 where the solubility values are given in $\mathrm{mg}$ Asn $\cdot \mathrm{H}_{2} \mathrm{O} / \mathrm{g} \mathrm{H}_{2} \mathrm{O}$. The solubility of $\mathrm{L}-\mathrm{Asn} \cdot \mathrm{H}_{2} \mathrm{O}$ increases with increasing temperature. The solubility of DL-Asn $\cdot \mathrm{H}_{2} \mathrm{O}$ is slightly more than twice the L-Asn $\cdot \mathrm{H}_{2} \mathrm{O}$ solubility and thus only approximately follows the Meyerhoffer solubility rule [25]. The current data agrees well with the single data point for aqueous systems of Orella and Kirwan [26], $28.7 \mathrm{mg} \mathrm{L}-\mathrm{Asp} \cdot \mathrm{H}_{2} \mathrm{O} / \mathrm{g}$ $\mathrm{H}_{2} \mathrm{O}$ at $25^{\circ} \mathrm{C}$. However the data for the L-Asn $\cdot \mathrm{H}_{2} \mathrm{O} / \mathrm{g} \mathrm{H}_{2} \mathrm{O}$ is around $4-5 \%$ lower than equivalent results of Dalton and Schmidt [27]: however that study is over 80 years old, and perhaps the purification of the amino acids was more difficult at that point. Solubility data 
over the entire range of temperatures measured agree very well with the recent data of Binev et al. [28].

Since D-Asn $\cdot \mathrm{H}_{2} \mathrm{O}$ and L-Asn $\cdot \mathrm{H}_{2} \mathrm{O}$ are a pair of enantiomers, the solubility and metastable zone width (MSZW) are the same for these species (in the absence of chiral additives, or if equivalent chiral additives are used). The solubility of $\mathrm{D}-\mathrm{Asn} \cdot \mathrm{H}_{2} \mathrm{O}$ with D-enantiomer additives is almost identical to the solubility of pure $\mathrm{D}-\mathrm{Asn} \cdot \mathrm{H}_{2} \mathrm{O}$ (by comparison to the solubility of pure L-Asn $\cdot \mathrm{H}_{2} \mathrm{O}$ ). It was found that the D-enantiomer additives do have an effect on the MSZW of D-Asn $\cdot \mathrm{H}_{2} \mathrm{O}$. The results are very scattered, but the additives appear to slightly increase the MSZW of D-Asn $\cdot \mathrm{H}_{2} \mathrm{O}$, and also increase the range of possible values. Equivalent effects would be seen for the effect of L-additives on L-Asn $\cdot \mathrm{H}_{2} \mathrm{O}$. The MSZWs for the DL-Asn $\cdot \mathrm{H}_{2} \mathrm{O}$ systems are significantly larger than those from the previous studies [28]. This is curious since both studies used identical techniques and equipment (the Crystal16, multiple reactor system). It is known that the MSZW is reliant on the nucleation rates of the solute, and so is very sensitive to small changes in the properties of the measurement device and also to the properties of the solution, for instance trace levels of impurity and dust.

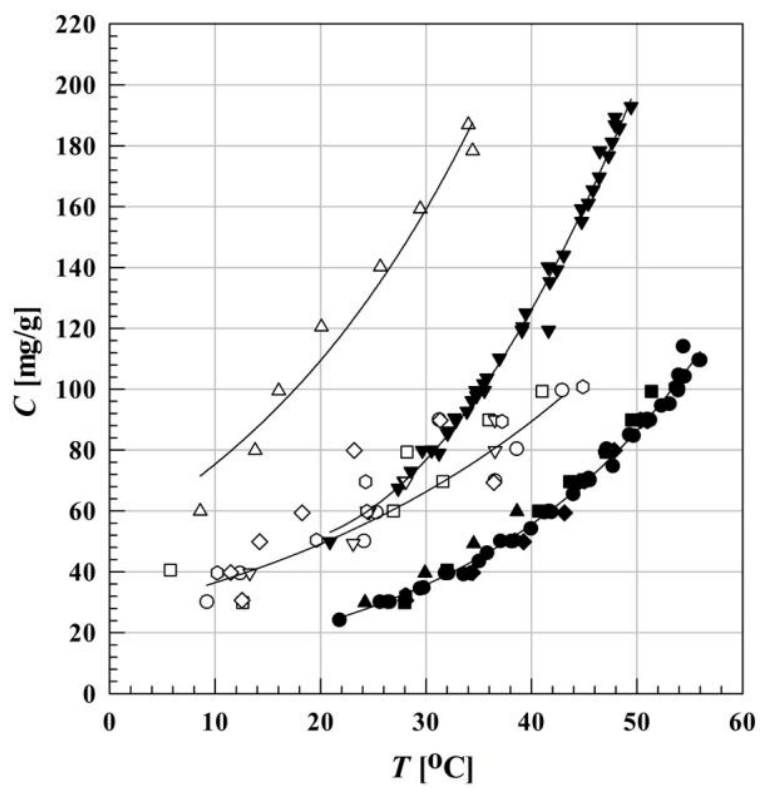

Figure 2. The solubility and metastable limit of L-/DL-Asn $\cdot \mathrm{H}_{2} \mathrm{O}$ with and without additives in water. Solubility points consist of L-Asn $\cdot \mathrm{H}_{2} \mathrm{O}(\bullet), \mathrm{DL}-\mathrm{Asn} \cdot \mathrm{H}_{2} \mathrm{O}(\boldsymbol{\nabla}), \mathrm{D}-\mathrm{Asn} \cdot \mathrm{H}_{2} \mathrm{O}$ with D-Asp ( $)$, D-Asn $\cdot \mathrm{H}_{2} \mathrm{O}$ with D-Leu $(\diamond)$, D-Asn $\cdot \mathrm{H}_{2} \mathrm{O}$ with D-Glu $(\boldsymbol{\Delta})$, DAsn $\cdot \mathrm{H}_{2} \mathrm{O}$ with D-Val ( ), and cloud points consist of L-Asn $\cdot \mathrm{H}_{2} \mathrm{O}(\mathrm{O}), \mathrm{DL}-\mathrm{Asn} \cdot \mathrm{H}_{2} \mathrm{O}$ $(\triangle)$, D-Asn $\cdot \mathrm{H}_{2} \mathrm{O}$ with D-Asp ( $\left.\square\right)$, D-Asn $\cdot \mathrm{H}_{2} \mathrm{O}$ with D-Leu $(\diamond), \mathrm{D}-\mathrm{Asn} \cdot \mathrm{H}_{2} \mathrm{O}$ with DGlu $(\nabla)$, and D-Asn $\cdot \mathrm{H}_{2} \mathrm{O}$ with D-Val $(\bigcirc)$. The lines are guide to the eye. 


\subsection{Crystal Growth Rate of $\mathrm{L}-\mathrm{Asn} \cdot \mathrm{H}_{2} \mathrm{O}$ in $\mathrm{L}-/ \mathrm{DL}-\mathrm{Asn} \cdot \mathrm{H}_{2} \mathrm{O}$ with additives}

The shape of crystals of $\mathrm{L}-\mathrm{Asn} \cdot \mathrm{H}_{2} \mathrm{O}$ grown from aqueous solution at various times is shown in Figure 3. We used the length of the principal axis of the crystal to find the crystal growth rate. The crystal growth rate of each L-Asn $\cdot \mathrm{H}_{2} \mathrm{O}$ crystal in solution can be found from the slope of the plot between the length of crystal and time as shown in Figure 4.
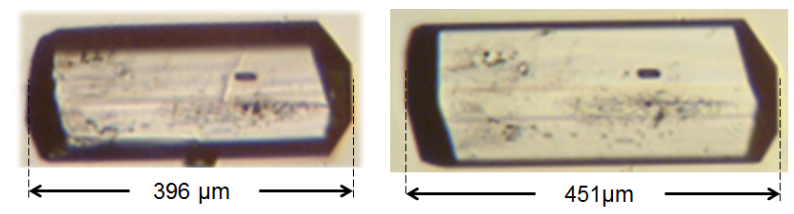

Figure 3. Crystal shape of L-Asn $\cdot \mathrm{H}_{2} \mathrm{O}$ in DL-Asn $\cdot \mathrm{H}_{2} \mathrm{O}$ with supersaturation, $\mathrm{S}$ equal to 1.1 at (a) 0 min and (b) $80 \mathrm{~min}$

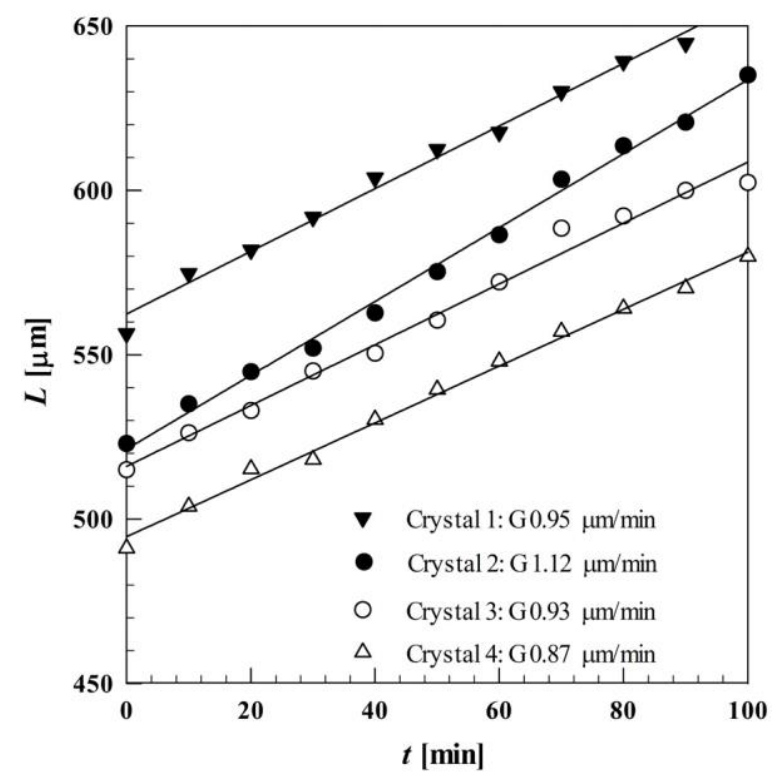

(a) 


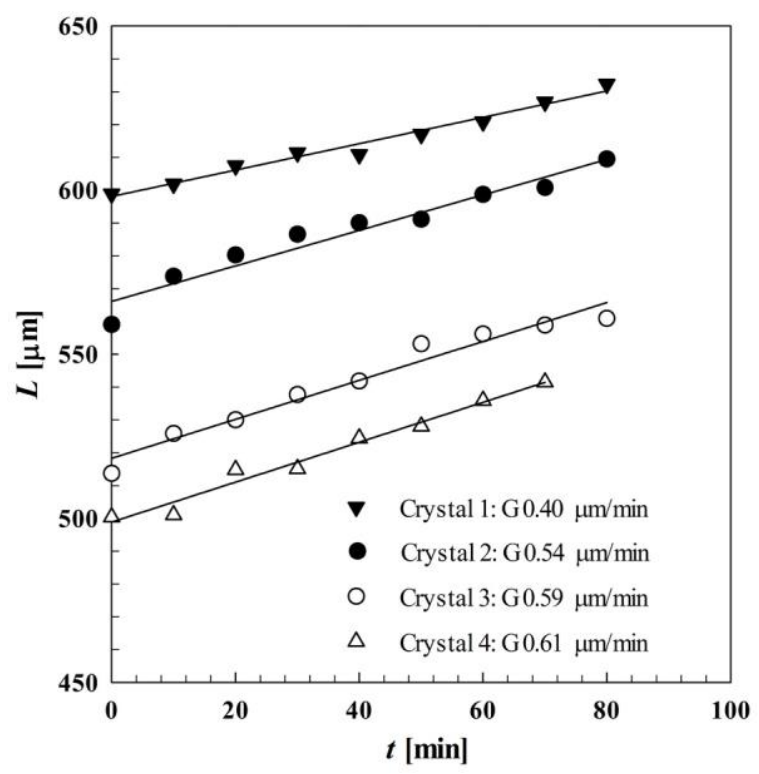

(b)

Figure 4. Relationship between crystal size (length) of L-Asn $\cdot \mathrm{H}_{2} \mathrm{O}$ and time in supersaturated solution $\left(\mathrm{S}=1.1\right.$ ) of (a) $\mathrm{L}-\mathrm{Asn} \cdot \mathrm{H}_{2} \mathrm{O}$ and (b) DL-Asn $\cdot \mathrm{H}_{2} \mathrm{O}$ at $30^{\circ} \mathrm{C}$.

The crystal growth rate of L-Asn $\cdot \mathrm{H}_{2} \mathrm{O}$ crystals in supersaturated solutions of L- and DLAsn $\cdot \mathrm{H}_{2} \mathrm{O}$, and DL-Asn $\cdot \mathrm{H}_{2} \mathrm{O}$ with $\mathrm{D} / \mathrm{L}$ - additives can be plotted as growth rate distributions, growth rate frequency vs growth rate of $\mathrm{L}-\mathrm{Asn} \cdot \mathrm{H}_{2} \mathrm{O}$, as shown in Figure 5, and also modeled based on the normal distribution, eq 1.

$$
f_{G}(G)=a \cdot \exp \left(\frac{\left(G-G_{0}\right)^{2}}{2 \sigma_{G}^{2}}\right)
$$

where $f_{G}$ is the growth rate frequency, $G$ is the crystal growth rate, $G_{0}$ is the mean growth rate of the distribution, $\sigma_{\mathrm{G}}$ is the standard deviation of the growth rate distribution, and $a$ is a parameter relating only to the total number of samples in the distribution [29]. While there is no a priori knowledge of the shape of the growth rate distributions, the distributions found are relatively narrow and fit the normal distribution quite well.

The fitting parameters for the crystal growth rate of $\mathrm{L}-\mathrm{Asn} \cdot \mathrm{H}_{2} \mathrm{O}$ crystals in various supersaturated solutions of L- and DL-Asn $\cdot \mathrm{H}_{2} \mathrm{O}$ are shown in Table 1 and in supersaturated solutions of DL-Asn $\cdot \mathrm{H}_{2} \mathrm{O}$ with $3 \mathrm{~mol} \%$ of D-/L- additives in Table 2.

Table 1: Fitting parameters for the crystal growth rate distribution of $\mathrm{L}-\mathrm{Asn} \cdot \mathrm{H}_{2} \mathrm{O}$ grown in solutions of L- and DL-Asn $\cdot \mathrm{H}_{2} \mathrm{O}$ in various supersaturation.

\begin{tabular}{lll}
\hline$S$ & L-Asn $\cdot \mathrm{H}_{2} \mathrm{O}$ solution & DL-Asn $\cdot \mathrm{H}_{2} \mathrm{O}$ solution \\
\hline
\end{tabular}




\begin{tabular}{ccccccc}
\hline & 1.05 & 1.1 & 1.15 & 1.05 & 1.1 & 1.15 \\
\hline$G_{o}(\mu \mathrm{m} / \mathrm{min})$ & 0.51 & 0.96 & 1.41 & 0.29 & 0.60 & 0.89 \\
$\sigma_{G}$ & 0.09 & 0.11 & 0.12 & 0.07 & 0.11 & 0.18 \\
$R^{2}$ & 0.9972 & 0.9835 & 0.9360 & 0.9985 & 0.9423 & 0.9765 \\
\hline
\end{tabular}

Table 2: Fitting parameters for the crystal growth rate distribution of $\mathrm{L}-\mathrm{Asn} \cdot \mathrm{H}_{2} \mathrm{O}$ grown in solutions of DL-Asn $\cdot \mathrm{H}_{2} \mathrm{O}$ without and with $3 \mathrm{~mol} \%$ (based on total concentration of DL$\mathrm{AsnH}_{2} \mathrm{O}$ ) of various additives at a supersaturation $S=1.1$.

\begin{tabular}{cccccccccc}
\hline Type of additives & no additives & D-Asp & D-Glu & D-Leu & D-Val & L-Asp & L-Glu & L-Leu & L-Val \\
\hline$G_{o}(\mu \mathrm{m} / \mathrm{min})$ & 0.60 & 0.39 & 0.47 & 0.69 & 0.60 & 0.19 & 0.28 & 0.62 & 0.73 \\
$\sigma_{G}$ & 0.11 & 0.07 & 0.09 & 0.11 & 0.08 & 0.06 & 0.06 & 0.12 & 0.07 \\
$R^{2}$ & 0.9423 & 0.9903 & 0.9995 & 0.9824 & 0.9844 & 0.9643 & 0.9974 & 0.9829 & 0.8964 \\
\hline
\end{tabular}

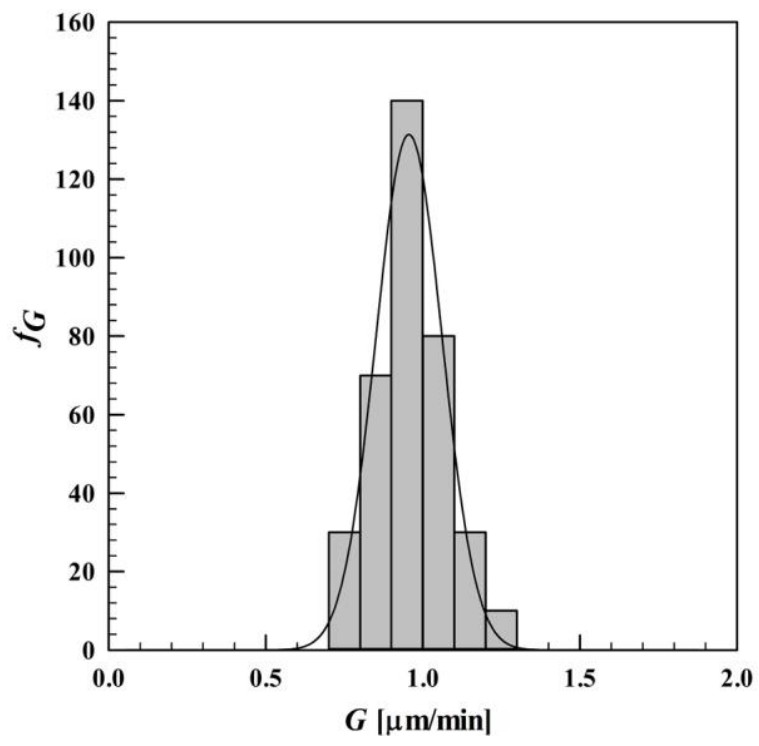

(a)

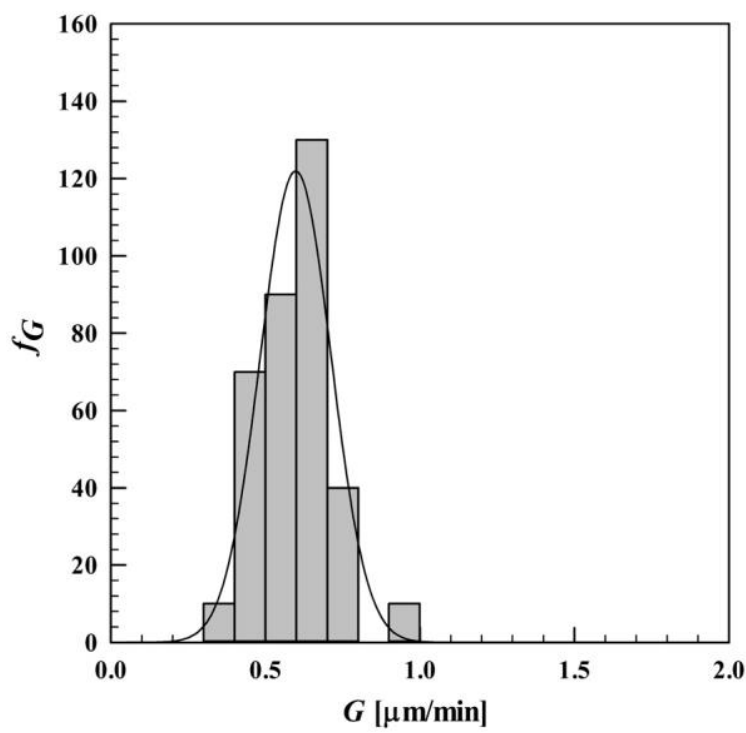

(b) 
Figure 5. Relationship between growth rate frequency and growth rate of L-Asn $\cdot \mathrm{H}_{2} \mathrm{O}$ crystals in a solution with supersaturation, $\mathrm{S}=1.1$ of (a) $\mathrm{L}-\mathrm{Asn} \cdot \mathrm{H}_{2} \mathrm{O}$ (b) $\mathrm{DL}-\mathrm{Asn} \cdot \mathrm{H}_{2} \mathrm{O}$ at $30^{\circ} \mathrm{C}$.

The growth rate of $\mathrm{L}-\mathrm{Asn} \cdot \mathrm{H}_{2} \mathrm{O}$ in $\mathrm{L}-\mathrm{Asn} \cdot \mathrm{H}_{2} \mathrm{O}$ solution was the highest; for the same supersaturation of $\mathrm{L}-\mathrm{Asn} \cdot \mathrm{H}_{2} \mathrm{O}$ the growth from DL-Asn $\cdot \mathrm{H}_{2} \mathrm{O}$ solutions was substantially reduced, with an almost 50\% reduction in growth rates at low supersaturation values. One explanation for this difference is that the counter enantiomer acts as an inhibitor to the growth of the preferred enantiomer. It is possible that even in compounds where the conglomerate is the stable crystal form, the association of the preferred and counter enantiomer (as would be seen in the racemate form) is still strong enough that the counter enantiomer of the additive can also adsorb to the surface of the crystal and inhibit the growth of the conglomerate form. Another possible explanation is that racemic dimers of Asn (associations of D- and Lmolecules) in solution hinders the supply of L- monomers to the surface of the crystal and thus lowers the crystal growth rate.

From Table 2, the mean growth rate of L-Asn $\cdot \mathrm{H}_{2} \mathrm{O}$ with D-Val and L-Leu additives are not statistically different from the growth rate without additives. Use of D-Leu as an additive increases the growth rate, however the change is only slightly larger than the $95 \%$ confidence limits. Use of L-Val as an additive increases the growth rate of L-Asn by a statistically significant amount. The reason for this is not known although the additive appears to have no significant effect on the solubility of L-Asn. It is possible that the molecule interrupts the associations between D- and L-Asn molecules in solution. D-Glu, D-Asp, L-Glu and L-Asp additives significantly reduced the crystal growth rate of $\mathrm{L}-\mathrm{Asn} \cdot \mathrm{H}_{2} \mathrm{O}$. This is to be expected because of the greater similarity of the side chains of aspartic acid and glutamic acid to asparagine, in comparison to the side chains of valine or leucine. However, there is a more significant effect of additives of the same chirality as the growing crystal; the effect of L-Glu and L-Asp on L-Asn $\cdot \mathrm{H}_{2} \mathrm{O}$ was greater than the D-Glu and D-Asp additives because L-Glu and L-Asp additives have the same absolute configuration as $\mathrm{L}-\mathrm{Asn} \cdot \mathrm{H}_{2} \mathrm{O}$. These additives are therefore likely to adsorb on the growing surface of $\mathrm{L}-\mathrm{Asn} \cdot \mathrm{H}_{2} \mathrm{O}$ and inhibit the propagation of the growth steps on the crystal.

For this experiment, we measured the growth in the length of the principal axis of the crystal, but the growth rate based on the spherical average diameter can be derived from this value based on the shape of the crystal. In the case investigated here it was found that there is minimal change in the shape of the crystal as the growth progresses even in experiments using 
additives, and therefore it seems that the additives cause a similar inhibiting effect for all important growth surfaces of the crystal.

Here L-Asn was used as the crystallizing species for convenience - it is easier to obtain commercially than D-Asn. In the preferential crystallizations of L-Asn $\cdot \mathrm{H}_{2} \mathrm{O}$ we use D-Asp and D-Glu to inhibit growth of D-Asn $\cdot \mathrm{H}_{2} \mathrm{O}$.

\subsection{Preferential crystallization of $\mathrm{L}-\mathrm{Asn} \cdot \mathrm{H}_{2} \mathrm{O}$ with $\mathrm{D}$-Aspartic acid additives}

The preferential crystallization (PC) of L-Asn $\cdot \mathrm{H}_{2} \mathrm{O}$ from DL-Asn $\cdot \mathrm{H}_{2} \mathrm{O}$ with and without additives was studied. The enantiomeric excess $e$ of the produced crystals and yield $y$ of the PC were measured to show the effectiveness of the additives.

$$
e=\frac{C_{L}-C_{D}}{C_{L}+C_{D}} \times 100 \%=\frac{A_{L}-A_{D}}{A_{L}+A_{D}} \times 100 \%
$$

Where $C_{L}$ is the concentration of $\mathrm{L}-\mathrm{Asn} \cdot \mathrm{H}_{2} \mathrm{O}$ in the solid product (g L-Asn $\cdot \mathrm{H}_{2} \mathrm{O} / \mathrm{g}$ solid), $C_{\mathrm{D}}$ is the concentration of D-Asn $\cdot \mathrm{H}_{2} \mathrm{O}$ in the solid product, $A_{\mathrm{L}}$ and $A_{\mathrm{D}}$ are the peak areas of LAsn $\cdot \mathrm{H}_{2} \mathrm{O}$ and D-Asn $\cdot \mathrm{H}_{2} \mathrm{O}$ from the solid product in the HPLC chromatogram.

$$
y=\frac{m_{t}}{m_{t h}} \times 100 \%
$$

Here, $m_{t}$ is the mass of preferred enantiomer produced (which does not include the mass of the counter enantiomer in the product if the $e$ is less than 100\%) and $m_{\mathrm{th}}$ is maximum mass of the preferred enantiomer obtainable at equilibrium (again, excluding the counter enantiomer). Since a mass $m_{\mathrm{s}}$ of seed crystals was introduced at the start of the preferential crystallization resulting in a mass $m_{\mathrm{p}}$ of the preferred enantiomer product, the yield is further defined using $m_{t}=m_{p}-m_{s}$ in eq. 3 .

$$
y=\frac{m_{p}-m_{s}}{m_{t h}} \times 100 \%
$$

Figures 6-7 show the yield $y$ and enantiomeric excess $e$ of product in time respectively of the PC of L-Asn $\cdot \mathrm{H}_{2} \mathrm{O}$ in DL-Asn $\cdot \mathrm{H}_{2} \mathrm{O}$ with and without additives. The yield of the PC of LAsn $\cdot \mathrm{H}_{2} \mathrm{O}$ with and without additives increases with time. The yield of the PC of L-Asn $\cdot \mathrm{H}_{2} \mathrm{O}$ without additives can reach $60 \%$ within $7 \mathrm{~h}$. However, pure L-Asn $\cdot \mathrm{H}_{2} \mathrm{O}$ product can only be obtained within the initial $4 \mathrm{~h}$, with a yield of only $25 \%$ at this time: After $4 \mathrm{~h}$ of the crystallization nucleation and growth of D-Asn $\cdot \mathrm{H}_{2} \mathrm{O}$ occurs decreasing the enantiomeric excess $e$. 
Since the growth of the L-Asn $\cdot \mathrm{H}_{2} \mathrm{O}$ crystals was not close to completion at this time, the crystallization of D-Asn $\cdot \mathrm{H}_{2} \mathrm{O}$ should be inhibited to prolong the crystallization time through the use of additives. In the case of D-Leu and D-Val additives, similar yield and enantiomeric excess results are obtained compared to the PC without additives; this shows that they are not effective in inhibiting the crystallization of D-Asn $\cdot \mathrm{H}_{2} \mathrm{O}$. However, D-Glu and D-Asp can extend the time period during which there is no crystallization of D-Asn $\cdot \mathrm{H}_{2} \mathrm{O}$, which increases the period during which pure L-Asn $\cdot \mathrm{H}_{2} \mathrm{O}$ can be formed to longer than $7 \mathrm{~h}$ and $10 \mathrm{~h}$ respectively.

Although the time period of preferential crystallization is increased, the yield of LAsn $\cdot \mathrm{H}_{2} \mathrm{O}$ is lower at the same crystallization time compared to the case where no additive is used. This indicates that these additives also seem to inhibit the crystallization of L-Asn $\cdot \mathrm{H}_{2} \mathrm{O}$, which is consistent with the growth rate experiments. Nevertheless, the maximum yield of pure L-Asn $\cdot \mathrm{H}_{2} \mathrm{O}$ from PC with D-Glu additive is $30 \%$, and with D-Asp additive is more than $44 \%$, as shown in Figure 8, which is higher than the potential yield in the absence of additives. Therefore, the additives are helpful for the PC process in purity and yield. It is interesting that the main effect seen in the PC experiments was a significant increase in the induction time required for noticeable nucleation of the counter enantiomer while the MSZW experiments showed that the additives had only a small effect on the zone width. This may be due to the higher supersaturations at which crystals appear in the MSZW measurements compared to the PC and growth experiments. At these higher supersaturations additives might be less effective in blocking the crystal growth and since the MSZW is at least partially determined by growth no substantial effects of the impurities were measured. Since the MSZW is determined by nucleation and subsequent growth while no substantial effects of the impurities on the MSZW were measured this suggests that nucleation only occurs at relatively high supersaturations at which the effect of the impurity on the growth is absent.

To increase yield and prolong the period for which the enantiomeric excess is close to $100 \%$ for the system using PC with additives, more seed crystals can be used. The current PC experiments were performed to investigate the mechanisms on which the additives act in order to improve the performance of the PC systems. In order to optimize PC processes it is also necessary to consider optimization in terms of all tunable parameters, including additive levels, temperature profiles during cooling, agitation levels, and the amount of seeds used. 


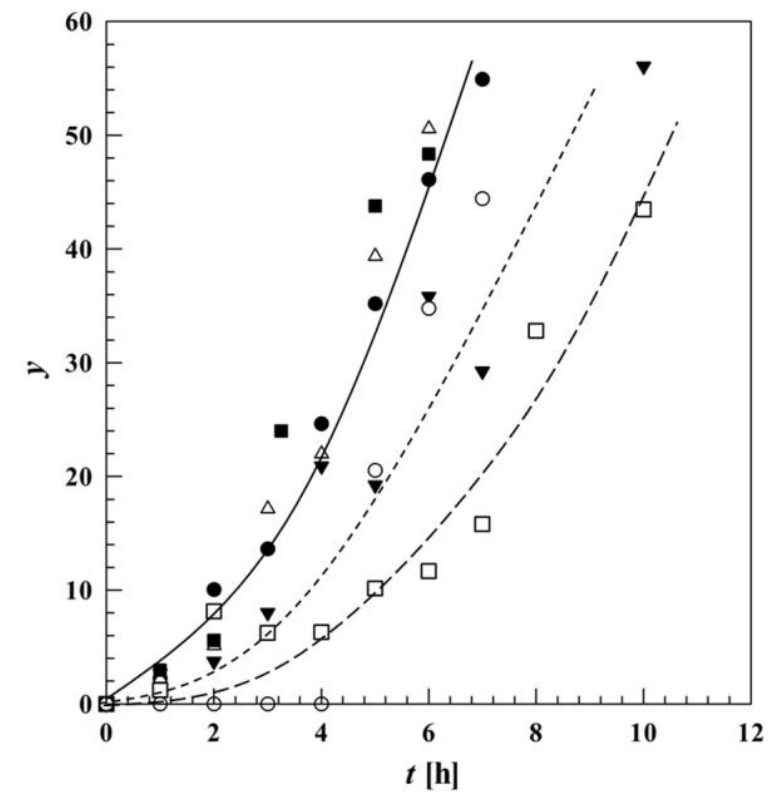

Figure 6. The yield $y$ of L-Asn $\cdot \mathrm{H}_{2} \mathrm{O}$ in the crystal phase during a preferential crystallization (PC) of L-Asn $\cdot \mathrm{H}_{2} \mathrm{O}$ from DL-Asn $\cdot \mathrm{H}_{2} \mathrm{O}$ in water in absence of additive (O), with $5 \%$ mol of D-Asp $(\square)$, with $5 \%$ mol of D-Glu $(\boldsymbol{\nabla})$, with $5 \%$ mol of D-Val $(\triangle)$, with $5 \%$ mol of D-Leu (ם), yield of D-Asn $\cdot \mathrm{H}_{2} \mathrm{O}$ from DL-Asn $\cdot \mathrm{H}_{2} \mathrm{O}$ in water in absence of additive $(\bigcirc)$. The lines are a guide to the eye.

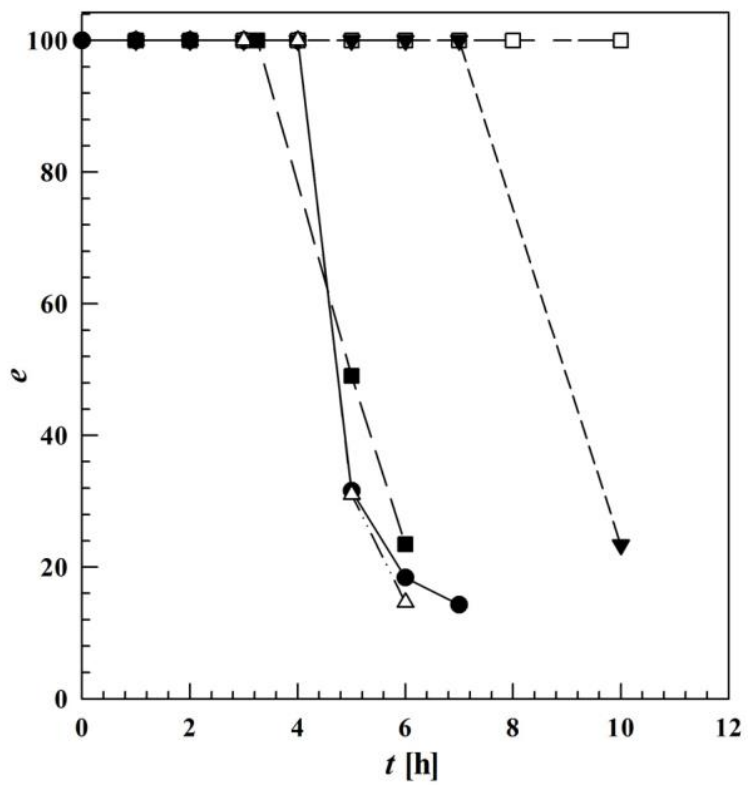

Figure 7. The enantiomeric excess $e$ of L-Asn $\cdot \mathrm{H}_{2} \mathrm{O}$ in the crystal phase during a preferential crystallization (PC) of L-Asn $\cdot \mathrm{H}_{2} \mathrm{O}$ from DL-Asn $\cdot \mathrm{H}_{2} \mathrm{O}$ in water in absence of additives ( ), with $5 \%$ mol of D-Asp ( $\square$ ) with $5 \%$ mol of D-Glu ( $\boldsymbol{\nabla}$ ), with $5 \%$ mol of D-Val $(\triangle)$, with $5 \%$ mol of D-Leu $(\square)$. The lines are a guide to the eye. 


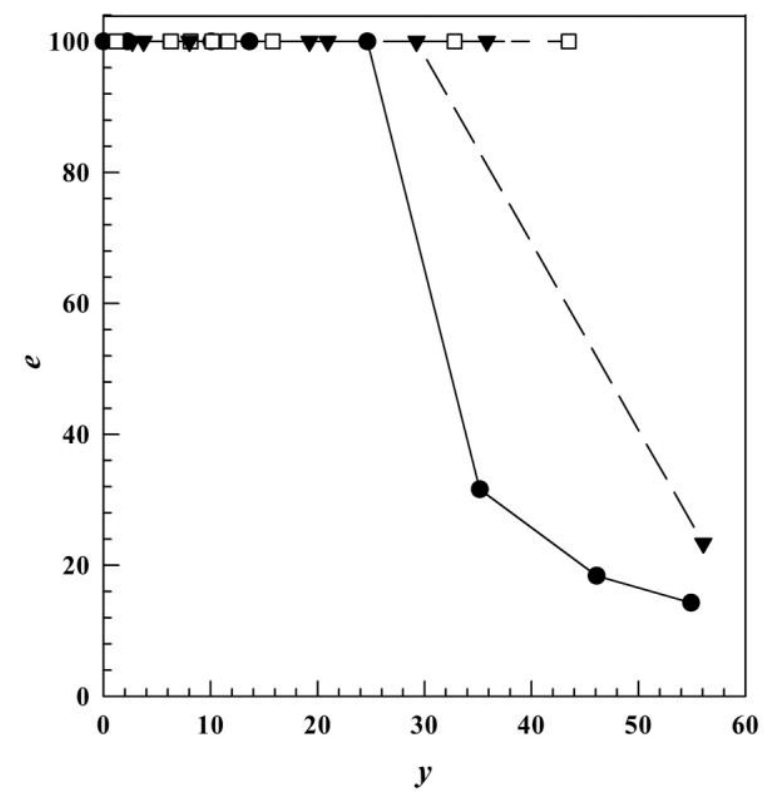

Figure 8. The relationship between enantiomeric excess $e$ and yield $y$ of L-Asn $\cdot \mathrm{H}_{2} \mathrm{O}$ from DL-Asn $\cdot \mathrm{H}_{2} \mathrm{O}$ in water in absence of additive (O), with $5 \%$ mol of D-Asp ( $\square$ ), with $5 \%$ mol of D-Glu $(\boldsymbol{\nabla})$. The lines are a guide to the eye.

\section{Conclusions}

The tested D-amino acids have almost no effect on the solubility of D-Asn $\cdot \mathrm{H}_{2} \mathrm{O}$ but have a slight effect on the metastable zone width of D-Asn $\cdot \mathrm{H}_{2} \mathrm{O}$, largely increasing the scatter or uncertainty of this zone. The growth rate of $\mathrm{L}-\mathrm{Asn} \cdot \mathrm{H}_{2} \mathrm{O}$ strongly decreases when using L-Asp and L-Glu additives in DL-Asn $\cdot \mathrm{H}_{2} \mathrm{O}$ solutions. The converse must also be true, that D-Asp and D-Glu inhibit crystallization of D-Asn $\cdot \mathrm{H}_{2} \mathrm{O}$ : These additives effectively prevent the crystallization of the counter enantiomer in the preferential crystallization of L-Asn $\cdot \mathrm{H}_{2} \mathrm{O}$. The success of these additives is likely due to the similarities in their side chains in comparison to asparagine. Leucine and valine have far less effect as additives; these two molecules have side chains that are alkanes, which are much less compatible with the side chain of asparagine which contains both carbonyl and amine functionality. However, at the same crystallization time the yield of L-Asn $\cdot \mathrm{H}_{2} \mathrm{O}$ decreases when D-Glu and D-Asp were used as additives. Therefore, the D-additives not only influence the crystallization of D-Asn $\cdot \mathrm{H}_{2} \mathrm{O}$ but also influence the crystallization of L-Asn $\cdot \mathrm{H}_{2} \mathrm{O}$. Nevertheless, the yield of L-Asn $\cdot \mathrm{H}_{2} \mathrm{O}$ at the end of the period during which pure L-Asn $\cdot \mathrm{H}_{2} \mathrm{O}$ can be produced is higher when using D-Asp and D-Glu additives, and can in principle be increased by adding more seed crystals. Therefore, these additives are promising for improving the preferential crystallization of this species. 


\section{Acknowledgements}

The research was supported by the Thailand Research Fund (TRF) via the Royal Golden Jubilee Ph.D. program (1.C.TS/52/B.1). PK thanks for the kind hospitality that he received upon his visit to the Intensified Reaction \& Separation Systems group at the Delft University of Technology in the Netherlands. JtH thanks the EPSRC Centre for Innovative Manufacturing in Continuous Manufacturing and Crystallisation (http://www.cmac.ac.uk) for supporting this work (EPSRC funding under grant reference: EP/I033459/1).

\section{References}

1. P.Y. Bruice, Organic Chemistry, 4th edn. (Pearson Prentice Hall, New Jersey, 2004)

2. X. J. Wang, H. Wiehler,.C.B. Ching, J. Chem. Eng. Data 48, 1092 (2003)

3. T. Eriksson, S. Bjorkman, P. Hoglund, Eur. J. Clin. Pharmacol. 57, 365 (2001)

4. M. Yoshikawa, A. Higuchi, in Encyclopedia of Membrane Science and Technology, edited by E.M.C. Hoek, V.V. Tarabara, (John Wiley \& Sons, Hoboken NJ, 2013)

5. E. Francotte, J. Chromatogr. A. 906, 379 (2001).

6. H. Lorenz, A. Perlberg, D. Sapoundjiev, M.P. Elsner, A. Seidel-Morgenstern, A. Chem. Eng. Process. 45, 863 (2006)

7. D. Kozma, CRC Handbook of Optical Resolution via Diastereomeric Salt Formation (CRC Press, Boca Raton, 2002)

8. J. Jacques, A. Collet, S. Wilen, Enantiomers, Racemates and Resolutions (John Wiley \& Sons, New York, 1981)

9. T. Buhse, D.K. Kondepudi, B. Hoskins, Chirality 11, 343 (1999)

10. K. Petruševska-Seebach, A. Seidel-Morgenstern, M.P. Elsner, Cryst. Growth Des. 11, $2149(2011)$

11. V.M. Profir, M. Matsuoka, Colloid Surface A. 164, 315 (2000)

12. W. Srimahaprom, A.E. Flood, J. Cryst. Growth 362, 88 (2013)

13. M.P. Elsner, G. Ziomek, A. Seidel-Morgenstern, AIChE J. 55, 640 (2009)

14. G. Levilain, M. Eicke, A. Seidel-Morgenstern, Cryst. Growth Des. 12, 5396 (2012)

15. M.J. Eicke, G. Levilain, A. Seidel-Morgenstern, A. Cryst. Growth Des. 13, 1638 (2013)

16. A. Svang-Ariyaskul, W.J. Koros, R.W. Rousseau, Chem. Eng. Sci. 64, 1980 (2009)

17. K. Würges, K. Petrusevska, S. Serci, S. Wilhelm, C. Wandrey, A. Seidel-Morgenstern, M.

P. Elsner, S. Lütz, J. Mol. Catal. B: Enzym. 58, 10 (2009)

18. K. Petrusevska-Seebach, K. Würges, A. Seidel-Morgenstern, S. Lütz, M. P. Elsner, Chem. Eng. Sci., 64, 2473 (2009) 
19. L. Addadi, J. van Mil, M. Lahav, J. Am. Chem. Soc. 103, 1249 (1981)

20. L. Addadi, S. Weinstein, E. Gati, I. Weissbuch, M. Lahav, J. Am. Chem. Soc. 104, 4610 (1982)

21. D.K. Kondepudi, M. Culha, Chirality 10, 238 (1998)

22. D.K. Kondepudi, K.E. Crook, Cryst. Growth Des. 5, 2173 (2005)

23. N. Doki, M. Yokota, S. Sasaki, N. Kubota, Cryst. Growth Des. 4, 1359 (2004)

24. S. Srisanga, J.H. ter Horst, Cryst. Growth Des. 10, 1808 (2010)

25. T. Izumi, D.G. Blackmond, Chem. Eur. J. 16, 3065 (2009)

26. C.J. Orella, D.J. Kirwan, Ind. Eng. Chem. Res. 30, 1040 (1991)

27. J.B. Dalton, C.L.A. Schmidt, J. Biol. Chem. 109, 241 (1935)

28. D. Binev, A. Seidel-Morgenstern, H. Lorenz, Cryst. Growth Des. 16, 1409 (2016)

29. P. Kongsamai, A. Maneedaeng, A.E. Flood, in Proceeding of the 5th Regional Conference on Chemical Engineering, Pattaya, Thailand, 2013 